\title{
Anatomy and Pathophysiology of Upper Airway Obstructive Sleep Apnoea: Review of the Current Literature
}

\author{
Shi Nee Tan, MD, RPSGT ${ }^{1,2}$, Hyung Chae Yang, MD, PhD¹, Sang Chul Lim, MD, PhD ${ }^{1}$ \\ 'Department of Otolaryngology-Head and Neck Surgery, Chonnam National University Medical School, Chonnam National University Hospital, \\ Gwangju, Korea \\ ${ }^{2}$ School of Medicine, Kumpulan Perubatan Johor (KPJ) University College, Nilai, Malaysia
}

\author{
Received: December 19, 2020 \\ Revised: May 11, 2021 \\ Accepted: June 7, 2021

\section{Correspondence} \\ Sang Chul Lim, MD, PhD \\ Department of Otolaryngology-Head \\ and Neck Surgery, \\ Chonnam National University Medical School, \\ Chonnam National University Hospital, \\ 42 Jebong-ro, Dong-gu, Gwangju 61469, Korea \\ Tel $+82-62-220-6776$ \\ Fax +82-62-228-7743 \\ E-mail correspondent.cnuhent@gmail.com
}

ORCID

Shi Nee Tan

https://orcid.org/0000-0002-2501-9424

Hyung Chae Yang

https://orcid.org/0000-0002-9187-1367

Sang Chul Lim

https://orcid.org/0000-0001-5610-1554

(c) This is an Open Access article distributed under the terms of the Creative Commons Attribution Non-Commercial License (https://creativecommons.org/licenses/by-nc/4.0) which permits unrestricted non-commercial use, distribution, and reproduction in any medium, provided the original work is properly cited.
The increasing prevalence of obstructive sleep apnoea (OSA) led to the need to understand upper airway (UA) anatomy and its contribution to the disease process. This review article summarises the current understanding of OSA development in adults. It focuses on UA anatomy and pathophysiology in anatomical subsites including the nasal cavity, soft tissue, and bony frameworks. This article also describes research trends in the context of anatomy. The research investigated pathophysiological phenotypes and their correlation with anatomy, phenotype labelling using drug-induced sleep endoscopy and their clinical characteristics, and recent updates regarding non-invasive tools for diagnosing sites of obstruction in individuals with OSA.

Sleep Med Res 2021;12(1):1-8

Key Words Airway obstruction; Sleep apnea, obstructive; Tongue; Pathophysiology;

Endoscopy; Methods.

\section{INTRODUCTION}

Obstructive sleep apnoea (OSA) is a chronic disease that has exhibited increasing prevalence trends since the turn of the century $[1,2]$. By definition, it is a sleep-related breathing disorder that occurs during sleep, in which a partial or complete halt of airflow occurs despite ongoing respiratory effort [2-6]. Unfortunately, this disorder remains undiagnosed in a substantial proportion of the population [6-9], making it crucial for all healthcare professionals to increase awareness in society and to screen individuals exhibiting signs and symptoms related to OSA.

Due to the various factors that contribute to OSA, it is essential to characterise the upper airway (UA) in relation to the surrounding tissues, anatomical structures, neuromuscular function, and facial skeletal morphology as potential risk factors for OSA.

This study focused on the understanding of the functional mechanism(s) of the UA and facial skeletal anatomy as the anatomical phenotype of OSA in its pathogenesis.

\section{STRUCTURAL AND PHYSIOLOGICAL DETERMINANTS OF OSA}

OSA is characterised by recurrent episodes of UA collapse during sleep $[8,10,11]$. It can occur at multiple levels at the site of the nose, nasopharynx, oropharynx, epiglottis, or hypopharynx in a different proportion in individual patients [12-15]. According to previous studies, the Starling resistor model describes the UA physiology (Fig. 1) [16-19]. 


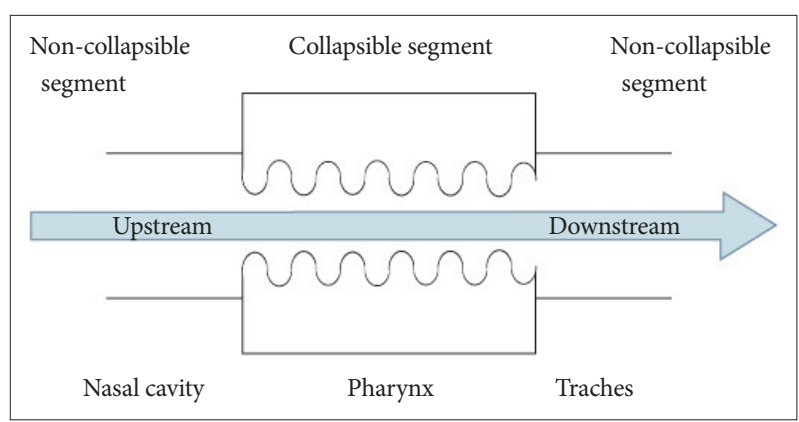

Fig. 1. Starling resistor model of the human upper airway describing the upstream segment (nasal cavity) and the downstream segment (trachea) as rigid tubes with the collapsible segment in the middle (pharynx).

\section{Nasal Region}

The nose is a non-collapsible structure and the initial entry site for air. It accounts for approximately $50 \%$ of the total airway resistance of the UA $[17,18]$. The nasal region, especially the internal nasal valve that comprised of septum, upper lateral cartilage, inferior turbinates, and nasal floor are the most important sites. Given that these entities comprise the narrowest portions of the nasal airway, aggravation of nasal obstruction is often found in OSA patients [20]. The nasal region in OSA can be explained by increased nasal airway resistance and the switch from nasal to mouth breathing due to nasal obstruction and impaired nasal ventilatory reflex.

\section{Increased nasal airway resistance}

The Starling resistor model reflects airway obstruction in accordance with an increase in nasal airway resistance. According to this model, suction forces are generated from the nose to the trachea during inhalation. An increase in nasal resistance generates greater negative pressure. However, the nose is a solid tube and will not collapse; as such, the collapsible pharyngeal segment is affected [18]. On the other hand, reduced in nasal resistance has been reported to improve UA patency $[21,22]$.

\section{Switch from nasal to mouth breathing}

One of the various factors in the nasal region that contributes to the development of OSA is the switch from nasal breathing to oral breathing. This condition commonly occurs during nasal obstruction caused by narrowing of the internal nasal valve area $[17,18]$. For sleeping subjects, UA resistance is greater in those breathing through their mouth than their nose [23]. On the other hand, for subjects that are awake, the UA resistance is equal for both forms of breathing [23]. In addition, mouth breathing narrows the pharyngeal lumen, reduces retroglossal diameter due to further posterior displacement of the tongue, increases soft palate length, and oscillates redundant pharyngeal tissues $[17,18$, 24-26]. Furthermore, prolonged mouth breathing may lead to facial changes which can lead to a narrow nasal floor and deviated nasal septum [27].

\section{Impaired or absent nasal ventilatory reflex}

Impaired or absent nasal ventilatory reflex occurs in mouth breathers. Mouth breathing reduces nasal receptor activation and subsequently impairs the nasal ventilatory reflex [28]. Impaired nasal ventilatory reflex reduces spontaneous ventilation $[23,28]$ causing failure of activation of the UA dilator muscles [23]. This condition worsens apnoea episodes because UA dilator muscle tone is inhibited, consequently reducing breathing and minute lung ventilation $[16,17,24,29]$.

\section{Nitric oxide}

Nitric oxide (NO) is believed to play a role in the pathogenesis of OSA and snoring; however, its mechanism of action is not well understood [30]. NO is produced in a significant amount within the nose and paranasal sinuses, and plays a role in perpetuating UA patency [17]. It functions as a potent bronchial dilator and increases blood oxygen content by reducing perfusion-ventilation mismatch [17,31]. Furthermore, It plays a role in managing muscle tone, neuromuscular control of the pharyngeal musculature, sleep, and regulation of breathing [17,31]. With all the known functions of $\mathrm{NO}$, the nasal region is a factor in the pathogenesis of OSA $[32,33]$. Therefore, this confirms that nasal obstruction is associated with snoring and OSA. In the presence of nasal obstruction, an increase in nasal resistance will occur, which may indirectly decrease the amount of NO and, therefore, nasal ventilation [32].

\section{Soft Tissue Morphology in OSA}

Fat deposition in the structure(s) surrounding the UA, such as the tongue, the soft tissue around the pharyngeal region, and pharyngeal muscles, can reduce the space occupied by the UA in those with OSA, especially in obese patients [34]. Changes in the anatomical phenotype of the soft tissue in OSA patients can effect physiological changes. Fig. 2 is a representative depiction of an unfavourable anatomy of the UA, which predisposes the patient to the development of OSA.

\section{Soft palate and retropalatal region}

Anatomically, the morphology of the soft palate in OSA patients appears to be thicker, longer, and increased in height, thus contributing to reduced airway dimensions [35-37]. The soft palate appears to be angled and thickened in this patient population $[37,38]$. In obese individuals, there is excessive deposition of the parapharyngeal fat pad extending to the submandibular space outside the maxillomandibular bony enclosure [39-42]. The presence of this excessive fat pad can further lead to concentric narrowing of the retropalatal pharynx, which consequently increases susceptibility to OSA [40,42]. Various researches have explained this phenomena as follows: increased mechanical load on the pharyngeal wall by the deposition of fat [43]; failure of the pharyngeal wall to sustain a higher passive critical closing pressure (Pcrit) than usual [44]; and an increase in collagen type 1 


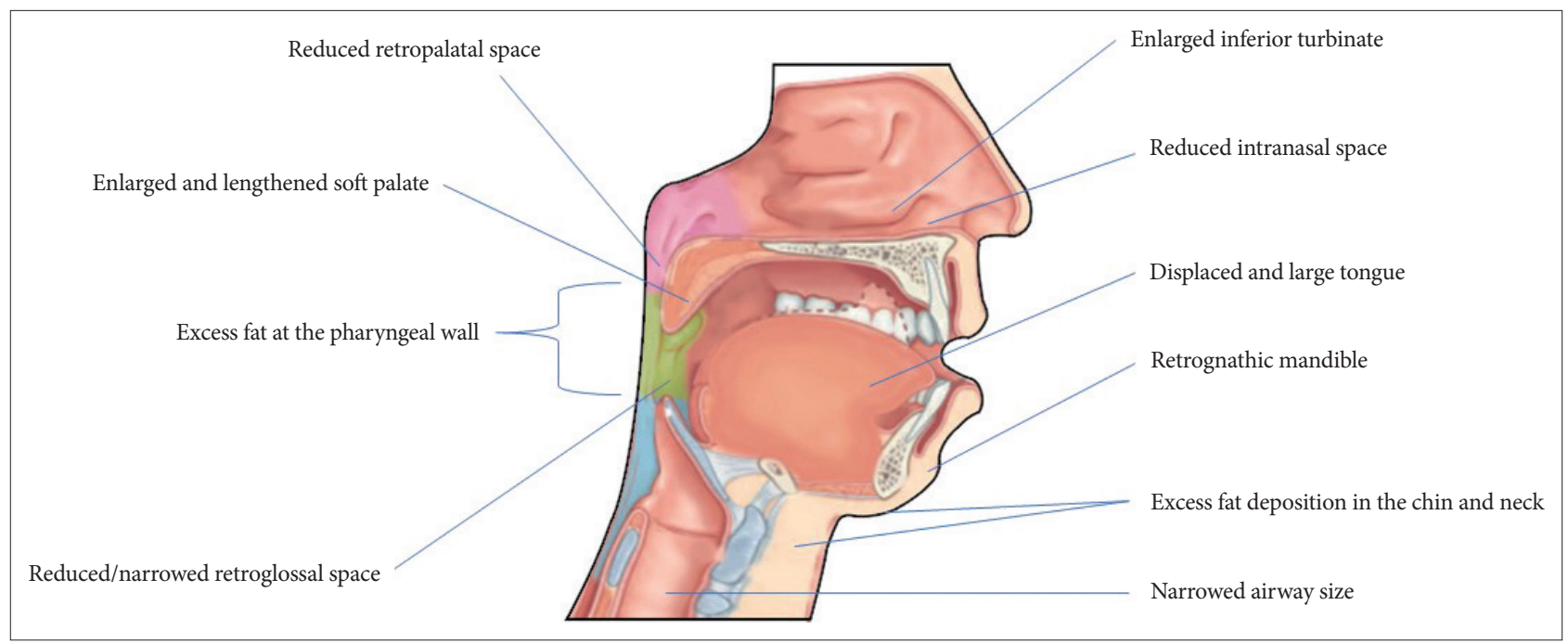

Fig. 2. Representative sagittal view of unfavourable upper airway anatomy, which may predispose patients to obstructive sleep apnoea.

in the extracellular matrix of the lateral pharyngeal wall, which can lead to impairment or delay relaxation of the superior pharyngeal constrictor muscles [45].

\section{Tongue}

The anatomy of the tongue in this patient population is somewhat contributory to OSA, owing to an increase in tongue volume or mass [34,46,47] and its more posterior position [48,49]. These combinations lead to significant retropalatal and retroglossal narrowing [50]. A study by Wang et al. [49], reported that weight loss had an effect in reducing the volume of several UA soft tissues, mainly tongue fat, in obese and OSA patients.

The physiological effect of the tongue in OSA is mainly correlated with tongue fat and the genioglossus (GG) muscle. During sleep onset, GG muscle activity reduces in both OSA patients and healthy individuals $[11,51,52]$. However, given the anatomical changes in OSA, this reduction will further exacerbate UA collapse. In individuals without OSA, negative airway pressure, hypoxia, and recurrent hypercapnia increase GG activity. However, this is usually insufficient to open the UA for adequate ventilation due to poor muscle responsiveness $[11,51,52]$. Eventually, this leads to arousal from sleep and, thus, elevated loop gain to increase the ventilatory drive to reopen the airway [53,54]. This could be due to various factors including: inadequate muscle recruitment in the GG muscles, thus requiring a higher level of respiratory stimuli $[6,55]$; poor neural response to GG muscles $[6,55]$; and distorted orientation of the muscle fibres and number of fast fibres in the tongue in patients with OSA, which are easily fatigued $[6,56]$. All of these factors contribute to reduced stiffness in the GG and, subsequently, lead to an increase in compliance to UA collapse. These factors are independent of body mass index (BMI) in patients with OSA [57].

\section{Facial Skeleton}

The facial skeleton is essential to airway patency. According to previous studies, the soft tissue within the maxillomandibular region and the bony structure enclosing it affects the size of the pharyngeal airway $[41,58,59]$.

\section{Maxilla and mandible}

Facial skeletal abnormalities, such as a small maxilla and/or mandible, are commonly encountered in patients with OSA. A small maxilla and mandible lead to a posteriorly positioned maxilla with a steep mandibular plane, leading to high upper and lower facial heights $[41,50,60]$. Due to these changes, there is overcrowding of the teeth by overeruption of the maxillary and mandibular teeth with proclined incisors. The position of the mandible determines the position of the tongue. Therefore, if the mandible and maxilla have a steep projection, both soft tissues (i.e., tongue and soft palate) are affected. All of these changes subsequently reduce available space for the UA [52].

A randomised case-controlled study by Suntherland et al. [61] recruited 363 OSA patients, 200 of whom were Chinese and 163 were Caucasian. According to the study, patients with OSA had reduced maxillary and mandibular depth angles. There were no interaction effects with sex or ethnicity, which means that these may be common OSA features in all groups. Furthermore, in a randomised case-controlled study by Tsuiki et al. [41], who compared the balance of craniofacial and tongue size between 50 OSA and 55 non-OSA subjects, the results revealed that patients with OSA had a significantly larger tongue, given the matched maxillomandibular dimension size. However, although the bony structure of the maxilla and mandible may limit soft tissue expansion, caudal expansion of the soft tissue in the oropharyngeal region remains possible [41].

A simple understanding is that obesity or facial skeletal abnormalities can aggravate narrowing of the UA (Fig. 3) [41,52,58]. 


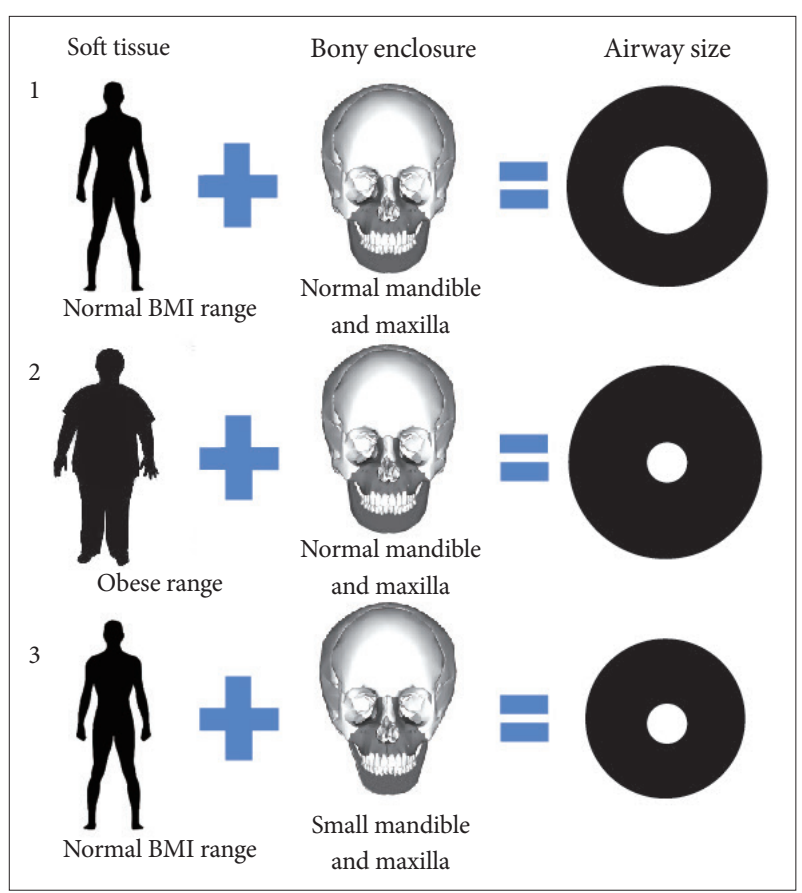

Fig. 3. Schematic representation of the combined interaction between the amount of soft tissue and bony enclosure of the upper airway and its effect on airway size. The highlighted part indicates soft tissue.

This is because they can increase Pcrit in the UA, thus contributing to the collapse of the pharyngeal segment in patients with OSA [58].

Therefore, balancing the ratio between the amount of soft tissue and the UA's facial skeleton's external bony enclosure are essential determinants of surrounding tissue pressure (Fig. 3) [58]. In conclusion, a disproportion of either can lead to narrowing of the UA.

\section{Hyoid bone}

The hyoid bone appears to be more inferiorly and posteriorly positioned in patients with OSA [38]. Since the hyoid bone is free and mobile and is not attached to other bones, expansion of the soft tissue caudally from the maxillomandibular bony enclosure may explain the shift of the hyoid bone caudally [58]. Furthermore, an increase in the distance between the hyoid and mandibular plane is of paramount consideration for OSA severity due to the attachment of the lingual musculature [52,62]. According to Starling model, increasing the distance increases the airway length, leading to instability $[52,63]$. In addition, the musculature attachments pull the tongue backward, causing narrowing of the pharyngeal airway $[38,41,58,64]$.

\section{RECENT RESEARCH TRENDS INVESTIGATING UA ANATOMY IN OSA}

This study focused on three recent research trends in OSA: pathophysiological phenotypes of OSA and anatomical traits; phenotype labelling with drug-induced sleep endoscopy (DISE) in patients with OSA; and non-invasive diagnostic tools for identifying anatomical factors affecting OSA.

\section{Pathophysiological Phenotypes of OSA and Anatomical Traits}

Understanding OSA phenotype is an important tool for designing strategies to identify and target interventions for patients at risk. Four important pathophysiological phenotypes of OSA have been discussed in most literature reviews $[11,51,55,65,66]$ : UA collapsibility, UA anatomy response to changes in Pcrit; muscle responsiveness, the capability of the UA dilator muscles to react to pharyngeal collapse (muscle responsiveness); low arousal threshold, wakefulness before muscle activation; and high loop gain and ventilatory loop gain changes in response to blood-gas disturbances during sleep. Given that the pathogenesis of OSA is multifactorial, it is important to understand the potential development of OSA using a combination of pathophysiological phenotypes and an anatomical predisposition $[6,51,55,67]$.

Generally, the UA in patients with OSA is usually smaller or narrowed compared to that in healthy individuals $[40,63,68]$. Furthermore, the soft tissues of the UA are unorganized. These factors lead to an increase in Pcrit and a predisposition to pharyngeal collapse [69]. Pierce et al. [26] reported that UA dilator muscle activation is directly proportional to Pcrit changes in awake OSA patients. The GG muscles activity was weakened with sleep onset in patients with OSA. Owing to the weakened response of the UA dilator muscles, UA patency is prone to collapse [11,51,52]. Subsequently, this would lead to arousal from sleep in patients with mild-to-moderate OSA with a low arousal threshold in response to increased negative pressure, hypoxia, or hypercapnia [56,70-72]. The feedback would stimulate high ventilatory loop gain to stabilize airway status $[53,54]$. A condition predominantly associated with severe OSA, in which patients exhibit a high arousal threshold and fail to respond to these stimuli [70], is believed to be due to neural plasticity in response to repetitive episodes of hypoxaemia [53]. They are more prone to hypoxia due to prolonged apnoea. In this condition, the high loop gain would be exaggerated due to the response of prolonged apnoea leading to hyperventilation to combat blood-gas instability $[53,54,66]$.

\section{Phenotype Labelling Using DISE in OSA}

The repetitive collapse of airway structures causes OSA. The site of obstruction can be identified using DISE, and each obstruction site may be correlated with an increase in OSA severity. However, some recent studies have reported a negative cor- 
relation between a specific type of anatomical obstruction and OSA severity $[15,73,74]$. This leads to the question of whether the collapse site identified using DISE can be regarded as a phenotype predicting overall disease severity.

\section{Velum}

Concentric narrowing in the retropalatal region (Vccc) is associated with the parapharyngeal fat pad [40]. Jang et al. [40] reported that the parapharyngeal fat pad does not act as a lateral mass, but as an increase in pharyngeal wall redundancy, which subsequently leads to an increase in surrounding pressure in the retropalatal region.

Hypoglossal nerve stimulation therapy is contraindicated in patients with Vccc identified on DISE [68,75]. However, Vccc exhibited poor response to surgical treatment [75-77]. Vccc and complete lateral collapse at the oropharyngeal level predict poor outcome(s) and treatment response in patients with mild-tomoderate OSA undergoing mandibular advancement device (MAD) therapy [78]. On the other hand, those with Vccc benefited from maxillomandibular advancement surgery in a prospective study [79]. Patients with Vccc required lower continuous positive airway pressure (CPAP) than those with anteroposterior velum collapse [80].

\section{Oropharynx}

Oropharyngeal lateral collapse is caused by thickening of the lateral pharyngeal wall and increase in the volume of the parapharyngeal fat pad $[81,82]$. A retrospective clinical review by Soares et al. [82] revealed that approximately $53 \%$ of OSA patients exhibited significant lateral oropharyngeal collapse at the retrolingual level, and that it was primarily observed in males, those with a higher BMI, and higher apnoea-hypopnoea index (AHI) than those who did not exhibit collapse. These findings corresponded with those reported in a cohort study by Schellenberg et al [83]. Furthermore, the study reported that enlargement or hypertrophy of the oropharyngeal soft tissue structures, such as the tonsils, soft palate, uvula, and tongue, also mediate the narrowing of the oropharyngeal airway [83].

There is a male predominance in oropharyngeal collapse; which according to a previous study, is hormonal [84]. Females exhibit decreased soft tissue volume in the neck and parapharyngeal fat despite higher percentages of body fat levels $[83,85]$. Females also exhibit increased pharyngeal dilator muscle activity. Thus, they exhibit a lower propensity for UA collapsibility than males; however, there are limited data supporting this assertion.

Regarding treatment options, this patient group exhibited a poor response to positional therapy [86] and palatal surgery [87]. However, they demonstrated a good response to CPAP treatment [80].

\section{Tongue}

The tongue is the most important anatomical factor in OSA
[48]. The effect of obesity has been reported to be dependent on tongue volume [49]. Thus, tongue base collapse and BMI are believed to be positively correlated. However, a recent DISE study revealed that tongue base obstruction and BMI were negatively correlated [88]. The study reported that tongue base obstruction was observed in all patients with low BMI (100\%) in the supine position [73]. This study highlighted an important clinical characteristic of OSA patients with a low BMI. In addition, these patients exhibited unfavourable characteristics for CPAP use [80] but demonstrated a good response to head rotation or MAD therapy $[15,78]$.

\section{Epiglottis}

The epiglottis is typically positioned in an upright position to facilitate air flow. Epiglottic "trapdoor" or floppiness has been reported in adults with sleep-related breathing disorders $[14,89,90]$, and can be identified using DISE. Nevertheless, Azarbarzin et al. [91] recently reported that discontinuity and "jaggedness" of airflow are the trademarks of epiglottic collapse in patients with OSA. Epiglottis collapse is exacerbated by the application of CPAP $[74,89,92]$. In such a situation, partial epiglottectomy has been shown to improve residual AHI [74]. In addition, patients with epiglottic collapse exhibited less severe OSA and lower BMI [15, 88]. Thus, they demonstrated a good response to non-CPAP treatments such as positional therapy or MAD $[14,15,88]$. However, the pathophysiology regarding how and why it occurs remains controversial.

\section{RECENT UPDATE REGARDING NON-INVASIVE DIAGNOSTIC TOOLS FOR IDENTIFYING ANATOMICAL FACTORS IN OSA}

The development of non-invasive tools to diagnose OSA is a topic of ongoing research and has resulted in new and emerging technologies $[46,93,94]$. Huang et al. [46] examined the impact of dynamic changes in tongue base thickness (TBT) in OSA during awake and sleep using DISE ultrasonography. Results revealed that TBT during DISE ultrasonography was significantly higher in sedated sleep state than that during the awake state and was positively correlated with AHI. This was the first study to demonstrate the feasibility of applying DISE ultrasonography to detect UA changes in patients with OSA.

Furthermore, Op de Beeck et al. [95] used a pneumotachometer to investigate flow measurement and performed shape analysis during DISE to identify the sites of UA collapse. The study revealed that patients with epiglottic collapse had significantly higher negative effort dependence (NED) values than those without epiglottic collapse. The breaths in epiglottic collapse have significantly higher NED than those in complete oropharyngeal, tongue base, or lateral pharyngeal wall collapse. 
Various studies have used commercially available software to perform computational fluid dynamics (CFD) analysis of the human UA. CFD can integrate structural analysis software using a fluid-structure interaction simulation to tackle human UA problems which involve movement, motion, and deformation of soft tissue or airway wall. This approach can be used to analyse and detect airway collapse during breathing [93]. In conjunction with CFD, MRI has been used to determine relationships between the retropalatal airway, pharyngeal length, and craniofacial structures in patients with OSA [94].

\section{CONCLUSION}

Studies aimed at elucidating the mechanism of OSA development are ongoing, and anatomy is an essential topic of investigation. Thus, consolidating anatomy with the pathophysiology of OSA is an essential step in future applications of precision medicine.

\section{Acknowledgments}

This research was supported by the Basic Science Research Program through the National Research Foundation of Korea, which is funded by the Ministry of Education (NRF2018R1D1A1B07046906), and a grant (BCRI-20054, 20071, 20027) from the Chonnam National University Hospital Biomedical Research Institute.

\section{Conflicts of Interest}

The authors have no financial conflicts of interest.

\section{Authors' Contribution}

Conceptualization: Lim SC, Yang HC. Data curation: all authors. Formal analysis: Lim SC, Yang HC. Funding acquisition: Lim SC, Yang HC. Investigation: all authors. Methodology: Tan SN, Yang HC. Project administration: Lim SC, Tan SN. Resources: Tan SN, Yang HC. Software: Tan SN, Yang HC. Supervision: Yang HC, Lim SC. Validation: Lim SC, Yang HC. Visualization: Lim SC, Tan SN. Writing_original draft: Tan SN. Writing—review \& editing: all authors.

\section{REFERENCES}

1. Benjafield AV, Ayas NT, Eastwood PR, Heinzer R, Ip MSM, Morrell MJ, et al. Estimation of the global prevalence and burden of obstructive sleep apnoea: a literature-based analysis. Lancet Respir Med 2019;7:68798.

2. Lyons MM, Bhatt NY, Pack AI, Magalang UJ. Global burden of sleepdisordered breathing and its implications. Respirology 2020;25:690702 .

3. Arnardottir ES, Bjornsdottir E, Olafsdottir KA, Benediktsdottir B, Gislason T. Obstructive sleep apnoea in the general population: highly prevalent but minimal symptoms. Eur Respir J 2016;47:194-202.

4. Gray EL, McKenzie DK, Eckert DJ. Obstructive sleep apnea without obesity is common and difficult to treat: evidence for a distinct pathophysiological phenotype. J Clin Sleep Med 2017;13:81-8.

5. Maspero C, Giannini L, Galbiati G, Rosso G, Farronato G. Obstructive sleep apnea syndrome: a literature review. Minerva Stomatol 2015; 64:97-109.

6. Zinchuk A, Yaggi HK. Phenotypic subtypes of OSA: a challenge and opportunity for precision medicine. Chest 2020;157:403-20.

7. Bjorvatn B, Lehmann S, Gulati S, Aurlien H, Pallesen S, Saxvig IW.
Prevalence of excessive sleepiness is higher whereas insomnia is lower with greater severity of obstructive sleep apnea. Sleep Breath 2015; 19:1387-93.

8. Osman AM, Carter SG, Carberry JC, Eckert DJ. Obstructive sleep apnea: current perspectives. Nat Sci Sleep 2018;10:21-34.

9. Motamedi KK, McClary AC, Amedee RG. Obstructive sleep apnea: a growing problem. Ochsner J 2009;9:149-53.

10. Ye L, Pien GW, Ratcliffe SJ, Björnsdottir E, Arnardottir ES, Pack AI, et al. The different clinical faces of obstructive sleep apnoea: a cluster analysis. Eur Respir J 2014;44:1600-7.

11. Zinchuk AV, Gentry MJ, Concato J, Yaggi HK. Phenotypes in obstructive sleep apnea: a definition, examples and evolution of approaches. Sleep Med Rev 2017;35:113-23.

12. Georgalas C, Garas G, Hadjihannas E, Oostra A. Assessment of obstruction level and selection of patients for obstructive sleep apnoea surgery: an evidence-based approach. J Laryngol Otol 2010;124:1-9.

13. Kotecha BT, Hannan SA, Khalil HM, Georgalas C, Bailey P. Sleep nasendoscopy: a 10-year retrospective audit study. Eur Arch Otorhinolaryngol 2007;264:1361-7.

14. Sung CM, Kim HC, Yang HC. The clinical characteristics of patients with an isolate epiglottic collapse. Auris Nasus Larynx 2020;47:450-7.

15. Kim HY, Sung CM, Jang HB, Kim HC, Lim SC, Yang HC. Patients with epiglottic collapse showed less severe obstructive sleep apnea and good response to treatment other than continuous positive airway pressure: a case-control study of 224 patients. J Clin Sleep Med 2021; 17:413-9.

16. McNicholas WT. The nose and OSA: variable nasal obstruction may be more important in pathophysiology than fixed obstruction. Eur Respir J 2008;32:3-8.

17. Georgalas C. The role of the nose in snoring and obstructive sleep apnoea: an update. Eur Arch Otorhinolaryngol 2011;268:1365-73.

18. Wilhelm CP, deShazo RD, Tamanna S, Ullah MI, Skipworth LB. The nose, upper airway, and obstructive sleep apnea. Ann Allergy Asthma Immunol 2015;115:96-102.

19. Ephros HD, Madani M, Yalamanchili SC. Surgical treatment of snoring \& obstructive sleep apnoea. Indian J Med Res 2010;131:267-76.

20. Liu SY, Riley RW, Yu MS. Surgical algorithm for obstructive sleep apnea: an update. Clin Exp Otorhinolaryngol 2020;13:215-24.

21. Yoon SH, Yang HC, Galiulina N, Kang TG, Kim HY, Lim HR, et al. The efficacy of nasal surgery on pharyngeal airway. Korean J Otorhinolaryngol-Head Neck Surg 2020;63:21-5.

22. Pang KP, Montevecchi F, Vicini C, Carrasco-Llatas M, Baptista PM, Olszewska E, et al. Does nasal surgery improve multilevel surgical outcome in obstructive sleep apnea: a multicenter study on 735 patients. Laryngoscope Investig Otolaryngol 2020;5:1233-9.

23. Fitzpatrick MF, McLean H, Urton AM, Tan A, O’Donnell D, Driver HS. Effect of nasal or oral breathing route on upper airway resistance during sleep. Eur Respir J 2003;22:827-32.

24. Lofaso F, Coste A, d'Ortho MP, Zerah-Lancner F, Delclaux C, Goldenberg F, et al. Nasal obstruction as a risk factor for sleep apnoea syndrome. Eur Respir J 2000;16:639-43.

25. Young T, Finn L, Kim H. Nasal obstruction as a risk factor for sleepdisordered breathing. J Allergy Clin Immunol 1997;99:S757-62.

26. Pierce R, White D, Malhotra A, Edwards JK, Kleverlaan D, Palmer L, et al. Upper airway collapsibility, dilator muscle activation and resistance in sleep apnoea. Eur Respir J 2007;30:345-53.

27. Williams R, Patel V, Chen YF, Tangbumrungtham N, Thamboo A, Most SP, et al. The upper airway nasal complex: structural contribution to persistent nasal obstruction. Otolaryngol Head Neck Surg 2019; 161:171-7.

28. Kohler M, Bloch KE, Stradling JR. The role of the nose in the pathogenesis of obstructive sleep apnoea and snoring. Eur Respir J 2007;30: 1208-15.

29. Poirrier AL, Eloy P, Rombaux P. Nose and sleep breathing disorders. In: Önerci TM. Nasal physiology and pathophysiology of nasal disorders. Heidelberg: Springer 2013;293-311. 
30. Haight JS, Djupesland PG. Nitric oxide (NO) and obstructive sleep apnea (OSA). Sleep Breath 2003;7:53-61.

31. Badran M, Golbidi S, Ayas N, Laher I. Nitric oxide bioavailability in obstructive sleep apnea: interplay of asymmetric dimethylarginine and free radicals. Sleep Disord 2015;2015:387801.

32. Michels Dde S, Rodrigues Ada M, Nakanishi M, Sampaio AL, Venosa AR. Nasal involvement in obstructive sleep apnea syndrome. Int $J$ Otolaryngol 2014;2014:717419.

33. Ip MS, Lam B, Chan LY, Zheng L, Tsang KW, Fung PC, et al. Circulating nitric oxide is suppressed in obstructive sleep apnea and is reversed by nasal continuous positive airway pressure. Am J Respir Crit Care Med 2000;162:2166-71.

34. Ono T. Tongue and upper airway function in subjects with and without obstructive sleep apnea. Jpn Dent Sci Rev 2012;48:71-80.

35. de Souza Pinto GN, Iwaki Filho L, Previdelli ITDS, Ramos AL, Yamashita AL, Stabile GAV, et al. Three-dimensional alterations in pharyngeal airspace, soft palate, and hyoid bone of class II and class III patients submitted to bimaxillary orthognathic surgery: a retrospective study. J Craniomaxillofac Surg 2019;47:883-94.

36. Kocakara G, Buyukcavus MH, Orhan H. Evaluation of pharyngeal airway dimensions and hyoid bone position according to craniofacial growth pattern. Cranio 2020 Jul 21 [Epub]. https://dx.doi.org/10.108 $0 / 08869634.2020 .1796060$.

37. Kurt G, Sisman C, Akin E, Akcam T. Cephalometric comparison of pharyngeal airway in snoring and non-snoring patients. Eur J Dent 2011;5:84-8.

38. Tsai HH, Ho CY, Lee PL, Tan CT. Cephalometric analysis of nonobese snorers either with or without obstructive sleep apnea syndrome. Angle Orthod 2007;77:1054-61.

39. Isono S. Obesity and obstructive sleep apnoea: mechanisms for increased collapsibility of the passive pharyngeal airway. Respirology 2012;17:32-42.

40. Jang MS, Kim HY, Dhong HJ, Chung SK, Hong SD, Cho HJ, et al. Effect of parapharyngeal fat on dynamic obstruction of the upper airway in patients with obstructive sleep apnea. Am J Respir Crit Care Med 2014;190:1318-21.

41. Tsuiki S, Isono S, Ishikawa T, Yamashiro Y, Tatsumi K, Nishino T. Anatomical balance of the upper airway and obstructive sleep apnea. Anesthesiology 2008;108:1009-15.

42. Feng Y, Keenan BT, Wang S, Leinwand S, Wiemken A, Pack AI, et al. Dynamic upper airway imaging during wakefulness in obese subjects with and without sleep apnea. Am J Respir Crit Care Med 2018;198: 1435-43.

43. Li Y, Lin N, Ye J, Chang Q, Han D, Sperry A. Upper airway fat tissue distribution in subjects with obstructive sleep apnea and its effect on retropalatal mechanical loads. Respir Care 2012;57:1098-105.

44. Pahkala R, Seppä J, Ikonen A, Smirnov G, Tuomilehto H. The impact of pharyngeal fat tissue on the pathogenesis of obstructive sleep apnea. Sleep Breath 2014;18:275-82.

45. Dantas DA, Mauad T, Silva LF, Lorenzi-Filho G, Formigoni GG, Cahali MB. The extracellular matrix of the lateral pharyngeal wall in obstructive sleep apnea. Sleep 2012;35:483-90.

46. Huang YC, Hsu YB, Lan MY, Yang MC, Kao MC, Huang TT, et al. Dynamic tongue base thickness measured by drug-induced sleep ultrasonography in patients with obstructive sleep apnea. J Formos Med Assoc 2021;120:354-60

47. Zaghw A, Shallik NA, El Geziry AF, Elhakeem A. Review of upper airway anatomy and its clinical application. In: Shallik NA, Moustafa $\mathrm{AH}$, Marcus MA. Virtual endoscopy and 3D reconstruction in the airways. Cham: Springer 2019;3-13.

48. Kim AM, Keenan BT, Jackson N, Chan EL, Staley B, Poptani H, et al. Tongue fat and its relationship to obstructive sleep apnea. Sleep 2014; 37:1639-48.

49. Wang SH, Keenan BT, Wiemken A, Zang Y, Staley B, Sarwer DB, et al. Effect of weight loss on upper airway anatomy and the apnea-hypopnea index. The importance of tongue fat. Am J Respir Crit Care
Med 2020;201:718-27.

50. Battagel JM, Johal A, Kotecha B. A cephalometric comparison of subjects with snoring and obstructive sleep apnoea. Eur J Orthod 2000; 22:353-65

51. Eckert DJ. Phenotypic approaches to obstructive sleep apnoea - New pathways for targeted therapy. Sleep Med Rev 2018;37:45-59.

52. Verbraecken JA, De Backer WA. Upper airway mechanics. Respiration 2009;78:121-33.

53. Subramani Y, Singh M, Wong J, Kushida CA, Malhotra A, Chung F. Understanding phenotypes of obstructive sleep apnea: applications in anesthesia, surgery, and perioperative medicine. Anesth Analg 2017; 124:179-91.

54. Wellman A, Jordan AS, Malhotra A, Fogel RB, Katz ES, Schory K, et al. Ventilatory control and airway anatomy in obstructive sleep apnea. Am J Respir Crit Care Med 2004;170:1225-32.

55. Eckert DJ, White DP, Jordan AS, Malhotra A, Wellman A. Defining phenotypic causes of obstructive sleep apnea. Identification of novel therapeutic targets. Am J Respir Crit Care Med 2013;188:996-1004.

56. Edwards BA, White DP. Control of the pharyngeal musculature during wakefulness and sleep: implications in normal controls and sleep apnea. Head Neck 2011;33(Suppl 1):S37-45.

57. Mediano O, Romero-Peralta S, Resano P, Cano-Pumarega I, Sánchez-de-la-Torre M, Castillo-García M, et al. Obstructive sleep apnea: emerging treatments targeting the genioglossus muscle. J Clin Med 2019;8:1754.

58. Watanabe T, Isono S, Tanaka A, Tanzawa H, Nishino T. Contribution of body habitus and craniofacial characteristics to segmental closing pressures of the passive pharynx in patients with sleep-disordered breathing. Am J Respir Crit Care Med 2002;165:260-5.

59. Isono $\mathrm{S}$, Tanaka A, Ishikawa T, Tagaito Y, Nishino T. Sniffing position improves pharyngeal airway patency in anesthetized patients with obstructive sleep apnea. Anesthesiology 2005;103:489-94.

60. Johal A, Patel SI, Battagel JM. The relationship between craniofacial anatomy and obstructive sleep apnoea: a case-controlled study. J Sleep Res 2007;16:319-26.

61. Sutherland K, Lee RWW, Chan TO, Ng S, Hui DS, Cistulli PA. Craniofacial phenotyping in Chinese and Caucasian patients with sleep apnea: influence of ethnicity and sex. J Clin Sleep Med 2018;14:114351.

62. Neelapu BC, Kharbanda OP, Sardana HK, Balachandran R, Sardana V, Kapoor P, et al. Craniofacial and upper airway morphology in adult obstructive sleep apnea patients: a systematic review and meta-analysis of cephalometric studies. Sleep Med Rev 2017;31:79-90.

63. Hsia JC. Anatomy and physiology of the upper airway in obstructive sleep apnea. Oper Tech Otolayngol Head Neck Surg 2015;26:74-7.

64. Riha RL, Brander P, Vennelle M, Douglas NJ. A cephalometric comparison of patients with the sleep apnea/hypopnea syndrome and their siblings. Sleep 2005;28:315-20.

65. Sands SA, Edwards BA, Terrill PI, Taranto-Montemurro L, Azarbarzin A, Marques M, et al. Phenotyping pharyngeal pathophysiology using polysomnography in patients with obstructive sleep apnea. Am J Respir Crit Care Med 2018;197:1187-97.

66. Tan SN, Abdullah B. Phenotypes of obstructive sleep apnea and direct targeted therapy: a literature review. Current Respiratory Medicine Reviews 2020;16:76-83.

67. Wellman A, Edwards BA, Sands SA, Owens RL, Nemati S, Butler J, et al. A simplified method for determining phenotypic traits in patients with obstructive sleep apnea. J Appl Physiol (1985) 2013;114:911-22.

68. Liu SY, Wayne Riley R, Pogrel A, Guilleminault C. Sleep surgery in the era of precision medicine. Atlas Oral Maxillofac Surg Clin North Am 2019;27:1-5.

69. Bosi M, De Vito A, Kotecha B, Viglietta L, Braghiroli A, Steier J, et al. Phenotyping the pathophysiology of obstructive sleep apnea using polygraphy/polysomnography: a review of the literature. Sleep Breath 2018;22:579-92.

70. Younes M. Role of arousals in the pathogenesis of obstructive sleep 
apnea. Am J Respir Crit Care Med 2004;169:623-33.

71. Edwards BA, Andara C, Landry S, Sands SA, Joosten SA, Owens RL, et al. Upper-airway collapsibility and loop gain predict the response to oral appliance therapy in patients with obstructive sleep apnea. Am J Respir Crit Care Med 2016;194:1413-22.

72. Edwards BA, Redline S, Sands SA, Owens RL. More than the sum of the respiratory events: personalized medicine approaches for obstructive sleep apnea. Am J Respir Crit Care Med 2019;200:691-703.

73. Woo HJ, Lim JH, Ahn JC, Lee YJ, Kim DY, Kim HJ, et al. Characteristics of obstructive sleep apnea patients with a low body mass index: emphasis on the obstruction site determined by drug-induced sleep endoscopy. Clin Exp Otorhinolaryngol 2020;13:415-21.

74. Jeong SH, Man Sung C, Lim SC, Yang HC. Partial epiglottectomy improves residual apnea-hypopnea index in patients with epiglottis collapse. J Clin Sleep Med 2020;16:1607-10.

75. Baptista PM, Costantino A, Moffa A, Rinaldi V, Casale M. Hypoglossal nerve stimulation in the treatment of obstructive sleep apnea: patient selection and new perspectives. Nat Sci Sleep 2020;12:151-9.

76. Koutsourelakis I, Safiruddin F, Ravesloot M, Zakynthinos S, de Vries $\mathrm{N}$. Surgery for obstructive sleep apnea: sleep endoscopy determinants of outcome. Laryngoscope 2012;122:2587-91.

77. Carrasco-Llatas M, de Apodaca PMR, de Castro JV, MatarredonaQuiles S, Dalmau-Galofre J. Drug-induced sleep endoscopy as a tool for surgical planning. Curr Otorhinolaryngol Rep 2019;7:1-9.

78. Op de Beeck S, Dieltjens M, Verbruggen AE, Vroegop AV, Wouters K, Hamans E, et al. Phenotypic labelling using drug-induced sleep endoscopy improves patient selection for mandibular advancement device outcome: a prospective study. J Clin Sleep Med 2019;15:1089-99.

79. Kastoer C, Op de Beeck S, Dom M, Neirinckx T, Verbraecken J, Braem MJ, et al. Drug-induced sleep endoscopy upper airway collapse patterns and maxillomandibular advancement. Laryngoscope 2020;130:E268-74.

80. Torre C, Liu SY, Kushida CA, Nekhendzy V, Huon LK, Capasso R. Impact of continuous positive airway pressure in patients with obstructive sleep apnea during drug-induced sleep endoscopy. Clin Otolaryngol 2017;42:1218-23.

81. Schwab RJ, Gupta KB, Gefter WB, Metzger LJ, Hoffman EA, Pack AI. Upper airway and soft tissue anatomy in normal subjects and patients with sleep-disordered breathing. Significance of the lateral pharyngeal walls. Am J Respir Crit Care Med 1995;152:1673-89.

82. Soares D, Sinawe H, Folbe AJ, Yoo G, Badr S, Rowley JA, et al. Lateral oropharyngeal wall and supraglottic airway collapse associated with failure in sleep apnea surgery. Laryngoscope 2012;122:473-9.

83. Schellenberg JB, Maislin G, Schwab RJ. Physical findings and the risk for obstructive sleep apnea. The importance of oropharyngeal struc- tures. Am J Respir Crit Care Med 2000;162:740-8.

84. Popovic RM, White DP. Upper airway muscle activity in normal women: influence of hormonal status. J Appl Physiol (1985) 1998;84: 1055-62.

85. Whittle AT, Marshall I, Mortimore IL, Wraith PK, Sellar RJ, Douglas NJ. Neck soft tissue and fat distribution: comparison between normal men and women by magnetic resonance imaging. Thorax 1999;54: 323-8.

86. Marques M, Genta PR, Sands SA, Azarbazin A, de Melo C, TarantoMontemurro L, et al. Effect of sleeping position on upper airway patency in obstructive sleep apnea is determined by the pharyngeal structure causing collapse. Sleep 2017;40:zsx005.

87. Green KK, Kent DT, D'Agostino MA, Hoff PT, Lin HS, Soose RJ, et al. Drug-induced sleep endoscopy and surgical outcomes: a multicenter cohort study. Laryngoscope 2019;129:761-70.

88. Sung CM, Tan SN, Shin MH, Lee J, Kim HC, Lim SC, et al. The site of airway collapse in sleep apnea, its associations with disease severity and obesity, and implications for mechanical interventions. Am J Respir Crit Care Med 2021 Apr 7 [Epub]. https://dx.doi.org/10.1164/ rccm.202011-4266LE.

89. Torre C, Camacho M, Liu SY, Huon LK, Capasso R. Epiglottis collapse in adult obstructive sleep apnea: a systematic review. Laryngoscope 2016;126:515-23.

90. da Cunha Viana A Jr, Mendes DL, de Andrade Lemes LN, Thuler LC, Neves DD, de Araújo-Melo MH. Drug-induced sleep endoscopy in the obstructive sleep apnea: comparison between NOHL and VOTE classifications. Eur Arch Otorhinolaryngol 2017;274:627-35.

91. Azarbarzin A, Marques M, Sands SA, Op de Beeck S, Genta PR, Taranto-Montemurro L, et al. Predicting epiglottic collapse in patients with obstructive sleep apnoea. Eur Respir J 2017;50:1700345.

92. Kent DT, Rogers R, Soose RJ. Drug-induced sedation endoscopy in the evaluation of OSA patients with incomplete oral appliance therapy response. Otolaryngol Head Neck Surg 2015;153:302-7.

93. Faizal WM, Ghazali NNN, Khor CY, Badruddin IA, Zainon MZ, Yazid AA, et al. Computational fluid dynamics modelling of human upper airway: a review. Comput Methods Programs Biomed 2020;196: 105627.

94. Avci S, Lakadamyali H, Lakadamyali H, Aydin E, Tekindal MA. Relationships among retropalatal airway, pharyngeal length, and craniofacial structures determined by magnetic resonance imaging in patients with obstructive sleep apnea. Sleep Breath 2019;23:103-15.

95. Op de Beeck S, Van de Perck E, Vena D, Kazemeini E, Dieltjens M, Willemen $\mathrm{M}$, et al. Flow-identified site of collapse during drug-induced sleep endoscopy: feasibility and preliminary results. Chest 2021; 159:828-32. 